\section{DIGITAL COMMONS \\ @ UNIVERSITY OF SOUTH FLORIDA}

Revista Surco Sur

6-30-2018

\title{
¡Sus majestades Enrique, Carlos y Flor Loynaz Muñoz!
}

Luis García de la Torre

Alejandro González Acosta

Follow this and additional works at: https://digitalcommons.usf.edu/surcosur

\section{Recommended Citation}

García de la Torre, Luis and Alejandro González Acosta. 2018. ¡Sus majestades Enrique, Carlos y Flor Loynaz Muñoz!. Revista Surco Sur, Vol. 8: Iss. 11, 12-21.

DOI: http://dx.doi.org/10.5038/2157-5231.8.11.6

Available at: https://digitalcommons.usf.edu/surcosur/vol8/iss11/8

This POESÍA is brought to you for free and open access by the Open Access Journals at Digital Commons @ University of South Florida. It has been accepted for inclusion in Revista Surco Sur by an authorized editor of Digital Commons@ University of South Florida. For more information, please contact digitalcommons@usf.edu. 


\section{Luis García de la Torre Alejandro González A costa}

\section{iS us majestades Enriquą Carlos y Flor L oynaz M uñozl}

Cuba, en los primeros años del siglo xx, fuetestigo del florecimiento de una familia deintelectuales de original contribución a la historia literaria de la lengua española. Hablamos de los hijos del General de Brigada del Ejército Libertador Enrique Loynaz del Castillo y de Doña María de las Mercedes Muñoz Sañudo: Enrique, Carlos Manuel y Flor, hermanos menores de quien fuera la más conocida y quien obtuvo el Premio de Literatura en Lengua Castellana "Miguel deCervantes": Dulce María Loynaz. Todos produjeron una lírica que les hizo pertenecer a la prole de poetas definitivos y fundamentales dentro de la literatura cubana e hispana.

Los hermanos Loynaz fueron creadores sucesivos sin yuxtaponerse mutuamente, ya que cada uno logró tal individualidad que a sus obras las caracterizó un contenido y una forma lírica, distinta una de otra, ejemplo singular en la historia de la literatura de lazo filial y literario.

Dulce María, la más estudiada, ineludiblemente ha tenido que reconocerse como la escritora cubana más importante del siglo xx, cuyo dominio de la prosa poética le permitió escribir su hoy canónica novela Jardín (1951). Enrique urdía versos y avaro los escondía, pero no lo suficiente ya que al develarse han destacado en la lumbre de la poesía cubana. Carlos Manuel quemó su producción, pero algo se rescató de aquellas implacables cenizas, por lo que toda obra suya tenida hoy es lujo y debe ser prioridad divulgarla. Y Flor en su palacio "Santa Bárbara", en La Habana, rodeada de perros y gatos, escribía poemas rebeldes y profundos acerca todo lo que estaba, vivía o respiraba en su mundo. ¿A caso no se adelantó así a las voces vanguardistas?

Para Enrique, Carlos Manuel y Flor, quienes serán los protagonistas de esta presentación, pareciera que nunca les resultó infinito el poder de sus versos y renegaban de publicarlos. Para los que los conocieron, les eran inmensos, pero los autores dimitían de sus creaciones y su validez. Entonces el proceso literario cubano tuvo que esperar. Para ellos, la revisión, las lecturas y el contacto con la gente, ese manoseo literario, les iba aniquilando la poesía, por lo que nunca o casi nunca quisieron participar del mismo. Hoy, y ahora, esta publicación se suma a las muy contadas que existen de y sobre ellos.

Enrique fue poeta y ensayista. Poseía un amplio conocimiento literario. Vivió en la escritura una realidad desasosegada en su yo interior, que le hizo ser leal, en interés y forma, a un tipo de lírica que dilató durante sus períodos más fértiles, y que se aparta de lo que se produjo en esos años de la República. Se dice que su poesía fue mística, pero también digo que veo en él muy presentes la carne y el vino que le hicieron escribir Los Poemas del A mor y del V ino, su libro más trabajado y por ende más logrado. Aquí se da a conocer un texto inédito de 1924, que no aparece en la publicación de 2004 del poemario, y en el cual se continúa revelando al Enrique que hace vida en lo mundanal. La gran Dulce María dijo de su hermano: "Adentrarse en la poesía de Enrique Loynaz es traspasar las fronteras de la realidad y el sueño con todos los riesgos que ello conlleva...".

Carlos Manuel Loynaz fue el más pequeño de los varones. Carlos poseía la habilidad del dibujo, la música y lo animaban a que escribiera poesía, Dulce María refiere: “....nuestro hermano Carlos Manuel, que nunca se doctoró, pudo adquirir una de las culturas más extensas que he conocido, al extremo que se le Ilamaba en el círculo íntimo, la Encidopedia Viva.(...) ...solo nuestro hermano Carlos $M$ anuel persistió en aquel rumbo; sus incursiones poéticas fueron breves, extrañas y esporádicas, bien que muy ponderadas por lo que pocos las conocieron, entre ellos Juan Ramón Jiménez y Lorca. Yo sigo pensando que su verdadero reino era la música. Ya desde sus primeros años dominaba el piano, y andando el tiempo se hizo un consumado ejecutante en el cual granaba un original compositor". Al reflexionar sobre su obra nos expresa: "... de lo que él quedó se deduce fue su estilo más leve, más aligerado de filosofía". 
En esta muestra que se brinda también tenemos el privilegio de contar con dos inéditos "Hermanita," escrito con tan solo veinte años y "La bruma", de una producción hecha entre los catorcey veintitrés. Se conservan muy pocos poemas suyos, por lo quees una verdadera riqueza esta entrega. Carlos Manuel, quien murió en 1977, es un poeta al que quisiéramos ver resucitado en el camino providencial de la poesía cubana, a medida que sus versos continúen siendo rescatados.

Por último, llega a la lírica de Cuba, y al mundo, la realeza de Flor Loynaz M uñoz con una poesía que no posee nada de lo que su siglo produjo. Sus versos van mucho más allá de una época, en contenido, en proceder y en espíritu. Toda su obra es testamento explícito sobre lo que nadie escribe, escribe primordial sobre lo que no se ve, y ve lo hecho por la genialidad dela vida, de la creación. Natural, se inclina al mundo como inspiración, ejemplo explícito vemos en uno de los poemas que se ofrecen "A una hoja de papel que me regaló Dulce María, regalo inconcebible en estos tiempos". Señorial, en sus registros, concebidos en soledad para la historia de las letras cubanas y universales. En sus poemas quedan variadas pistas de lo que fue su interés y dónde puso su amor, que motivó la fortuna de su dominio lírico, y por qué la poesía fue para ella un arte sublime y una necesidad de su expresión vital.

Nótese en referencias directas y oblicuas, ¿quizás algo de Darío en las mórbidas figuras femeninas que evoca Carlos Enrique?, la presencia intertextual de voces de otras épocas, como Omar Kayham, mencionado por Flor, pero también con presencia en Enrique, lo que atestigua la inmensa cultura que nutrió a todos los miembros de esta familia, ejemplo de acendrado criollismo cubano.

Lleguemos pues en esta edición no.11 de la R evista Surco Sur a la poesía de los tres hermanos de Dulce María. La revista hace honor a su nombre al facilitar la diseminación de esta poesía atesorada por la más famosa de los hermanos Loynaz que defendía, hasta en ese gesto de al bacea, la preservación de su linaje. Disfrutemos de las imágenes que muestran su clara y elegante caligrafía e imaginémosla copiando cuidadosamente estos versos para que atraviesen las épocas y lleguen a ustedes, lectores de Surco Sur. Dejemos pasar a la letra virtual denuestros días a la estirpe Loynaz que se muestra en estos poemas y poetas que son símbolos de toda una época habanera, pretérita, pero no perdida.

Además, el honor va por todas partes: Estas composiciones, copia del puño y letra de Dulce María Loynaz, llegan a publicarse por la amabilidad del Dr. A lejandro González A costa, tomadas de su Archivo Privado; y alzado todo y puesto en esta revista de las manos principales de la Dra. Madeline Cámara.

Reverencio tanta cubanía enamorada.
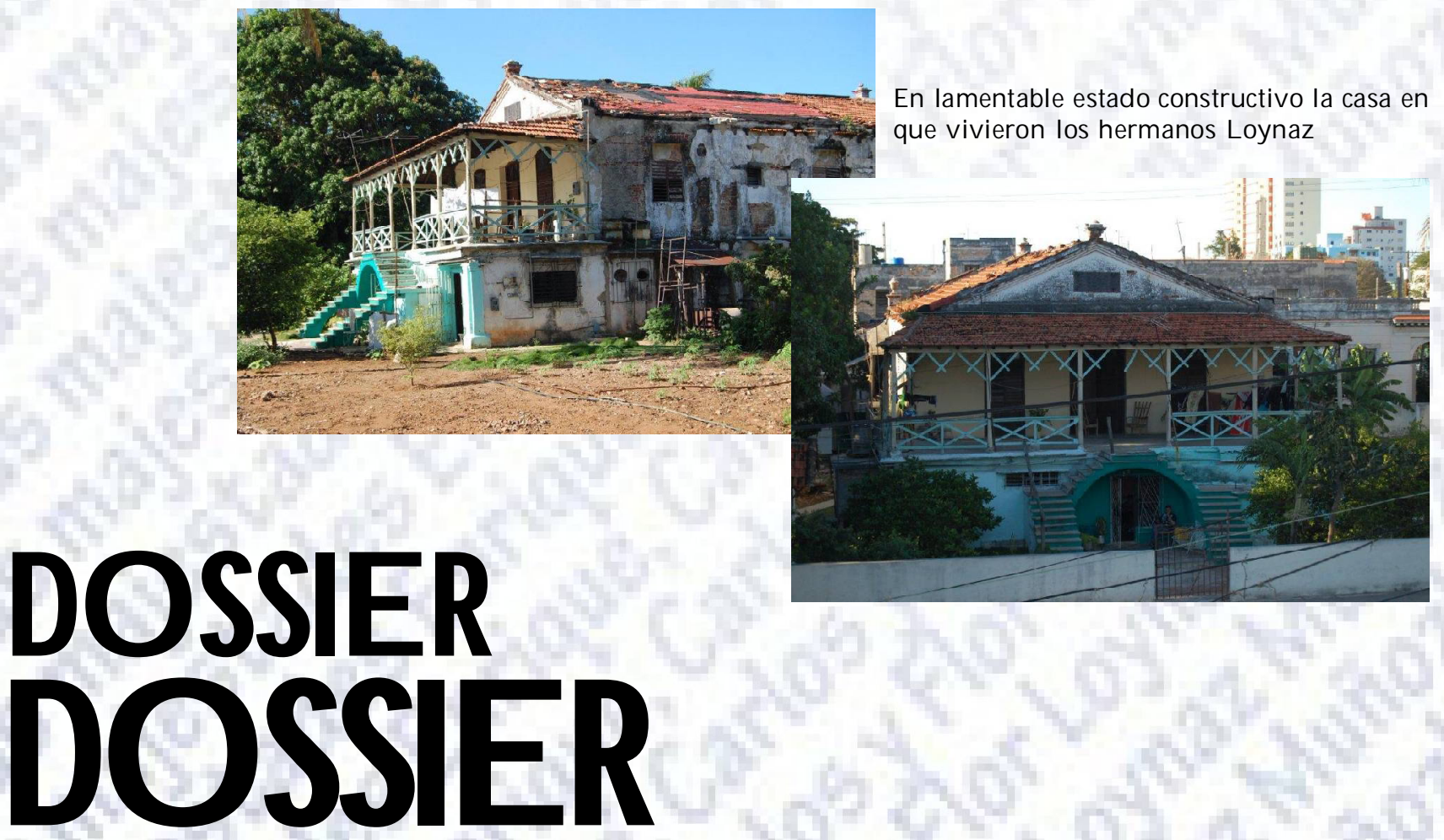


\section{Enrique Loynaz Muñoz}

\section{De Los poemas del A mor y del Vino}

Hay quien busca en el licor para sus penas olvido: yo bebo para saber que estoy vivo.

Bebo para hacer vivir muertos quellevo conmigo: las cenizas de mis sueños, de mi soledad los hijos.

Hijos que no tienen carne pero que ya tienen frío, y no hay calor en mi sangre bastante a darles abrigo.

Busco en esta copa un verso; un verso que nadie ha escrito. Bebo para hallar en Reino que me fuera prometido. El que antes de perder hube de dar por perdido.

De nada tengo que huir que de nada soy cautivo. Nada tengo que olvidar, solo busco lo quees mío.

Tal vez tú pienses, A mada, que milagros no hace el vino, que haber puede en una copa honduras como de abismo.

Mas, piensa que en esa hondura puede estar lo que yo ansío:

no la flor del asfódelo no el Nirvana de los místicos, menos fal sos cascabeles, menos sosiego de espíritu...

Bebo para recordar la vida que no he vivido.

De los foemas del cumor y del vino de Exri gue Rognay thining

selay quien busea suel leior para sule jentes obido:

Yobebo para saber

que estoy wivor

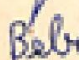

Bebo pala haces raver

mecestor cye elew cornmigo:

Ras cenifos de mis suerts.

de mi aedoll loo hijor.

odjos que no teren carne. pero que ya tínen pio. y no hay calor en hisurgre

dulante a dark abigo. Beaco on asta cona un veras: en verto qua madie ha everite. Belo tare hallar se Reun que the furse prometido. Ele que anta de perder

del archivo particular de Alejandro González A costa. 


\section{Poema IV}

No sé por qué, hoy tellevo

en mis labios, más adentro;

en mi pecho.

Más adentro... En mi corazón.

Hoy te siento

correr por mi sangre de fuego.

Hoy te siento cantar en mi silencio...

Más adentro,

Hoy te llevo en todo lo que tengo y aun no tengo,

en todo lo que deseo,

en todo lo que pienso

en todo lo que sueño,

en todo lo que busco... aún más adentro.

\section{Poema X}

¿De qué celestes uvas destilaron

el vino de tus besos?

¿Qué viñador sembró las vides

en los sutiles surcos de mi sueño?

¿Quién los racimos vendimió

y los llevó al lagar?

No acierto

a imaginar los pies de sombra

que un día se atrevieron

a hundirse entre su pulpa verdinegra,

a pisar sobre ellos.

Pies de sombra pisando

desprendidos luceros.

¿Quién pudo unir unos con otros,

reunir en solo un grano lo disperso?

Uvas iridiscentes con sabor

a luz, a nube, a vuelo...

¿Fue también quien sembró, el que estrujó?

A mada, pues que nunca lo sabremos,

déjame hoy saborear despacio

el dulce enigma de tus besos. del archivo particular de Alejandro González A costa.

$$
\begin{array}{r}
\text { Do hos foemas del amos y del vero } \\
\qquad \text { (Brique teyng) }
\end{array}
$$

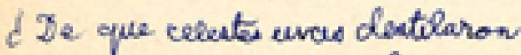

al who de tus boses?

¿que vitudeder semilio las vides

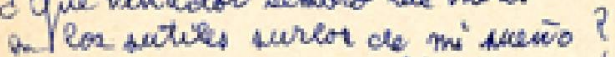

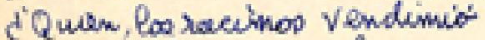

$y$ los lew's al engor?

a imaginar los jus de nombra

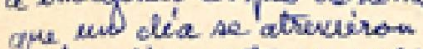

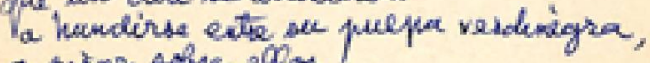
a phes othe thos.

Pide de tombla pinands

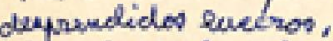

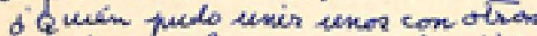

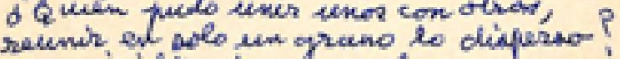

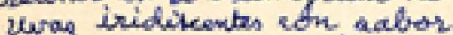

a \$4, a mabe, a vicilor i...

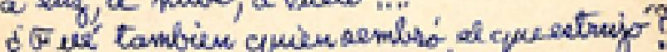

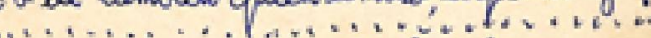

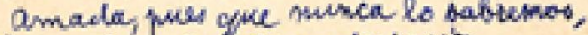
divame hag nabolear deyacit

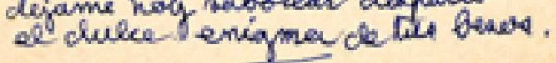

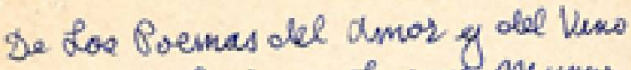

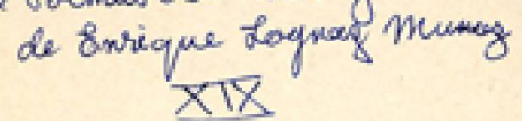

i Hujes negha ypopunde!

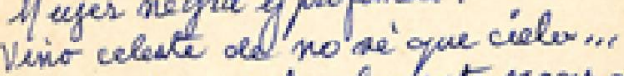
Nequo vino, profundanute negro; de que he bebelo:

\section{Poema XIX}

¡Mujer negra y profunda!

Vino celeste de no sé qué cielo...

Negro vino, profundamente negro,

del que he bebido. del archivo particular de Alejandro González A costa. 


\section{Carlos Manuel Loynaz Muñoz}

Hermanita

La niña se iba muriendo entre ropajes de lino; tus pies parecían los de un pajarito.

Para ella, cristal y flores (¡qué no nos oigan los niños!) Cuando ella se fue, cayeron unas cintas y unos lirios.

La niña se está muriendo... ¡Que tristes los piececitos! (ya los niños se quedaron Allá en las sombras dormidos.)

(Inédito - 1926)

\section{La bruma}

Como un pequeño insecto he caído en la bruma.

Sé que la bruma es nada, y soy el prisionero de la bruma.

(Inédito)

\section{Flores}

Flor negra y profunda. Tú, la más grave, la que se abre en el corazón - almendra, plexo solar de los árboles.

Y tú, flor blanca y terrible, la más grande, la que abre en las cumbres intocables.
La mina ab iba mureindo eutre ropajes de lino: sua pas paracion los de un pajorte.

tow ele, critel y fores

(ique no nos oigan hos niñes!) Clando elle he fue cayerom enar cintas y unar livios. Sa niña aedié muneridos. i Cue trente los presutos!

(Ya los miños as quedarom

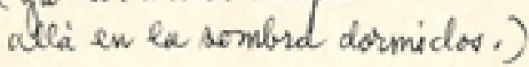

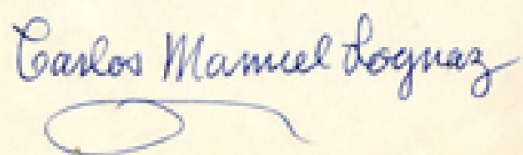

\section{Le Bruma}

Gomo un pequeño incelo he caido en fa brema. Se que la prewna es moda. y aby al priwioneso de le brenta.

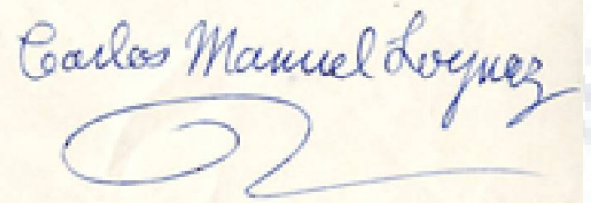

\section{Glores}

\section{Flos megra y pofinde. Tú} le mas yrave, la yue te abe en il cohagen-alnewdre. plevo soler de lor arboles.

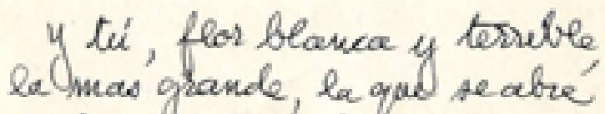
en las cumbses intorabes.

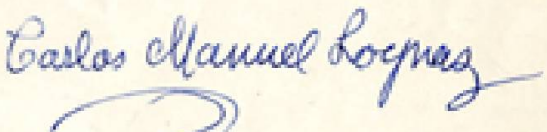




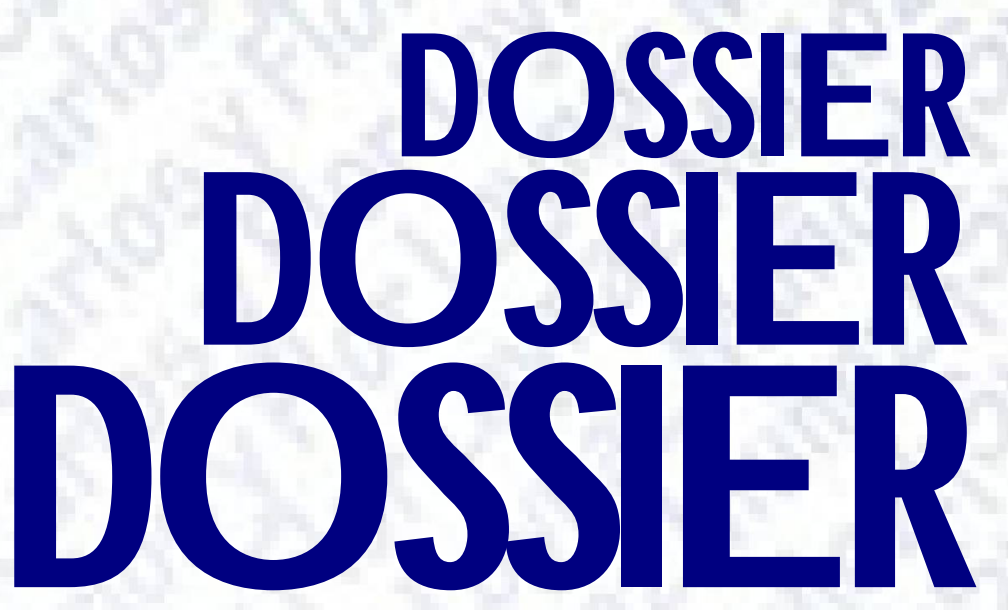

\section{Oyendo el Estudio 27 de Clementi}

Noche del conservatorio: la pequeña y dulce Ana hoy vino a tocar el piano. Tiene el aire de una garza; las alas se le han caído y no puede levantarlas.

Los caballeros de guante, dicen cosas a las damas, y de un abanico que cae se oye un rumor como de ala.

Niñas con clave de sol, cintas azules, rosadas... ¡N oche del conservatorio con traje de luminarias!

Y cuando el gran tío-vivo comienza ella se levanta -sus trenzas son oro purorompe los nervios que la atan, y va derechita al piano saltando entre las miradas sin caer... Nock ole convervatorio: Rapequeña y dulce ana hog lino athar el piare. Gilne te wine de vna garfas, la allas ne he har caldoI no puide leventarlas. Ler caballero de guante,

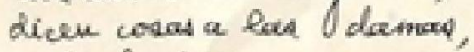
$y$ de abrice oue cas

He oge un wethor cornes de cela. lisina con chve de aAl, centos apulos, novades... i Nochedel 8 onerwatone con traje de lemsiarios! y cuardo ol gran tio-wio comiensa, ete 4 bucite - rus hogas am ore purodel archivo particular de Alejandro González A costa. 
Tararín...

(¿No ven cómo está de pálida?)

Tararín, tararán...

(Parece un lirio de aguas...)

Las notas chisporrotean

como luces de bengala.

Si una fusa o una corchea

se escapa del pentagrama,

ella la caza en el aire

tomándola por las alas.

La casa de Ana está lejos

en una calle arbolada.

Las tedas son las farolas

que de su umbral la separan.

Ya faltan pocas... Mas, jay!

ya la niña se desmaya.

Todos aplauden... No ven

la súplica en su mirada.

Ella sintió que sonreía

y las luces se apagaban...

Dejan sus guantes caer aquellos que los Ilevaban;

deja su atril el Maestro

sus abanicos las damas.

Vuelan girones de música

vuelan por toda la sala...

¡Y enterraron bajo el piano a la pequeña y dulce Ana!
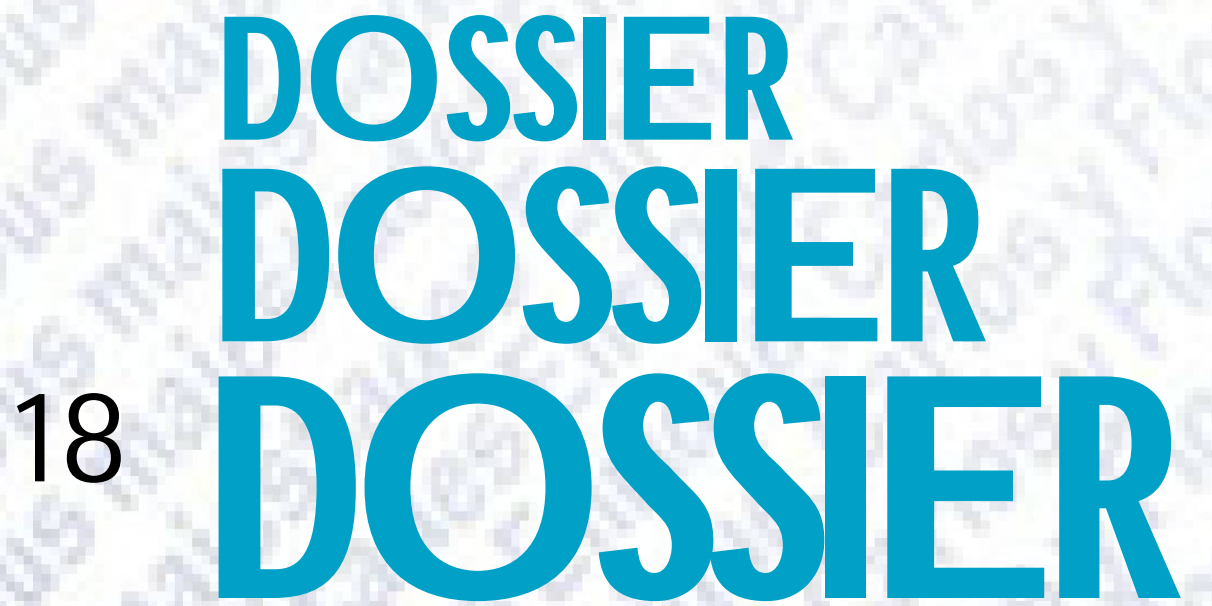

rompe los mericos ope lecetan

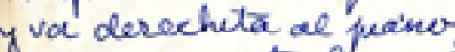

aactando evtre les miadas

als coench it

Toraren

(I Mover como esté ale palida?)

Gararin y tararan...

(Parve an brib de a geras)

Las motad chuporreter

come lues de tengrela.

Bi ura tua o wha cotclea

As excapa del pestagama,

ella la caya en el ario

tomandele pos las alas.

Ra cuse de ana eda lejos en une calle asbolada.

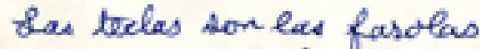

que de an sublal la deparan.

del archivo particular de Alejandro González A costa. 


\section{Flor Loynaz Muñoz}

A una hoja de papel que me regaló Dulce María, regalo inconcebible en estos tiempos

Es una fina hoja de papel con la que el viento alegre jugaría; ¡cuántas cosas en ella contaría que al corazón me suben en tropel!

Mas seguiré guardándolas en él, en esta delirante algarabía donde el Ilanto, la risa y la poesía se mezda como acíbar, sal y miel.

Dejemos esta hoja en su pureza guardando la palabra inmaculada. Si quiere, por el viento arrebatada andar el mundo... ¡Vuelve con presteza! que no será mi mano fatigada quien sujete su vuelo a mi tristeza.

\section{Amor}

De promesas falsas me hiciste un collar: filigrana de oro, cuentas de cristal-

Al verle tan frágil no lo quiero usar y como un tesoro escondido está.

Yo sé que hasta el viento lo puede quebrar.

\section{Qwior}

De promes fallas we bocite we collor:

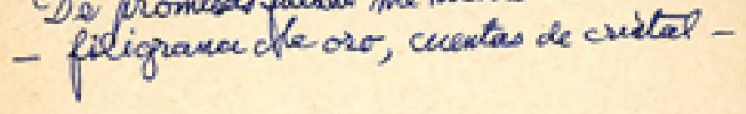
Qe verle tam fraigl moloquerte cuas y come un tedose encridiolo exl.

A ana hoja de papel que we regaló Dula Haria, regdo ilconeb beb en estor lowpod.

E. une fine hoje de payul

conla qu abyet el helto jugard:

i Purnta cona en ela contaria

que al corago'n the nuber en thopel!

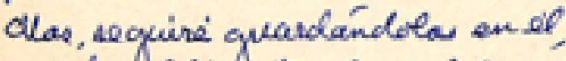
en edic dilishute algakabia donele el lanto, la trie y la presia ae meyclan come adibar, dal y nuble.

Dejemes esta hoja en the pertere. quadado la paladia rimacilada. OH oque, wor ce veito arrebtade.

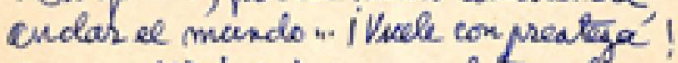
que no sord mi mino futroda quan augete are vado a the tristya.

GLordognag $19+6$

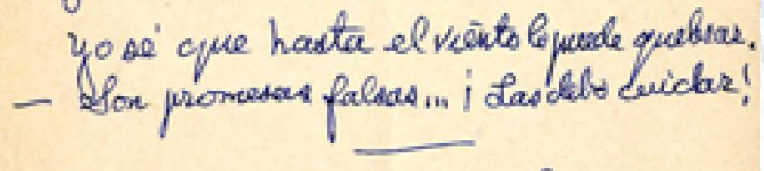
Glos boynay Son promesas falsas... iLas debo cuidar! 


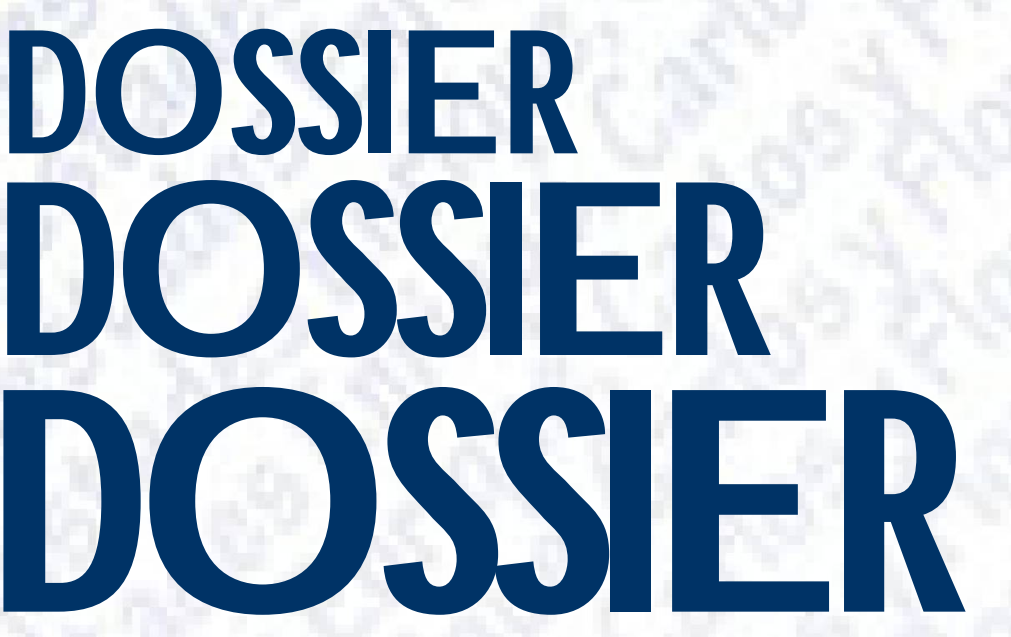

\section{Entierro loco}

Quietud, tristeza, muerte;

- Ha muerto como todo...-

ya enterrar su locura van los locos.

Lo llevan por un camino largo

o sin camino,

hacia blancuras de mármol.

Quieto: lo que no conocía reposo.

Callado: lo que fue alarido.

Fiebre: que se pasma ahora inerte.

Ya no queda risa ni sollozo.

Todo se va junto, apretado.

Los que lo llevan en hombros Iloran de cansancio.

No es día ni noche.

Luces y sombras arrastradas

por todas partes como bestias cansadas...

Tierra: boca abierta esperando.

Tierra: boca cerrada tragando.

Luego habrá defecación,

flores y mariposas y frutos en sazón

¡Muerto loco y locura!

Locos que entierran locos...

Se funden sombras, luces...

Y ahora todo es blancura.

(Sanatorio de Cruz de Piedra 1941 ó 42) del archivo particular de Alejandro González A costa.

$$
\text { Entwizo Row }
$$

Queted, ballez, mecrle;

- Ha muerto como todo... -

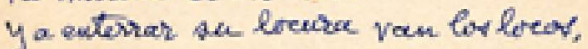

OL Vlevar por an cantio largo

- $\sin \cos u i a t$,

have Alanceras of masnot.

Quiets : Ro que mo convition repuras.

calouls: 2 que fué aloride.

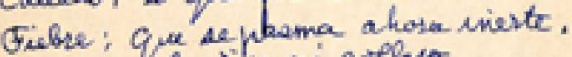

reve: que nise mi artboyo.

Yodo sa va jueb, apretado.

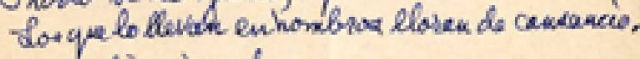
no es dia mi morhe.

thes y ambred arradiades

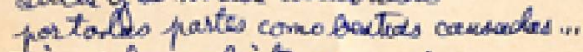

Tuise: boce aboste epreandor.

Gona:bece cerrade thagand.

Sueno habted defecicion

plora y maxyosas y frutes en agjox

TMuento des y bush !

foes que entibram bevo...

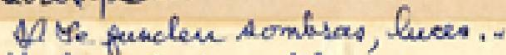

Y allota todo es blacucera.

Gantorio de Guy de Pubr 1941042 


\section{Tres poemas a Omar Khayan}

I

De ti, Omar Khayan, cantor del vino, espero la verdad:

De tu boca más fría y más amarga que el vino y queel mar.

De tus ojos que fueron como estrella quizás...

De tu corazón como vaso roto ha debido vaciar

el supremo dolor de la vendimia en el vino que se llega a tomar.

II

Aurora tras aurora

seguimos a Omar Khayan:

abandonándolo todo

por navegar.

Vamos por un mar de vino en un barco de cristal con los ojos embriagados de tanto mirar el mar.

No buscamos ningún puesto ni volvemos nunca más...

Vamos por un mar de vino esperando naufragar.

III

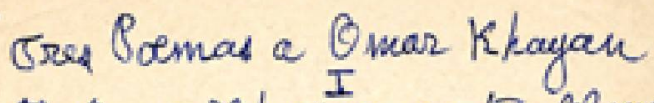
Dete, Omar Shayan, canlo de vehe entere ra verded:

op ta low mas bra y mas amarge que el vino y que el mas.

quiar a colagh que camo vaso roto ha olbide vacior

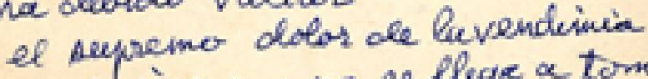
en al vino que no as eloge a tomar. II

Qurora tras awera, Aeguines a Omas Rhayan: abandonámelo zodo por navegar.

Vamos por un mar de venoen we bere de ereatel

com lis ofos embriagados

del archivo particular de Alejandro González A costa.

N osotros los que pasamos la vida cantando, los que juntamos guijarros de oro, los que nada hacemos ni nada pedimos porque en nuestra nada lo tenemos todo: nos iremos con Omar Khayan cantor del vino que nos espera ansioso de confiarnos su dulce secreto, guardado en los más obscuro del racimo, mientras Dios sonríe en el cielo y el sultán manda en su trono.

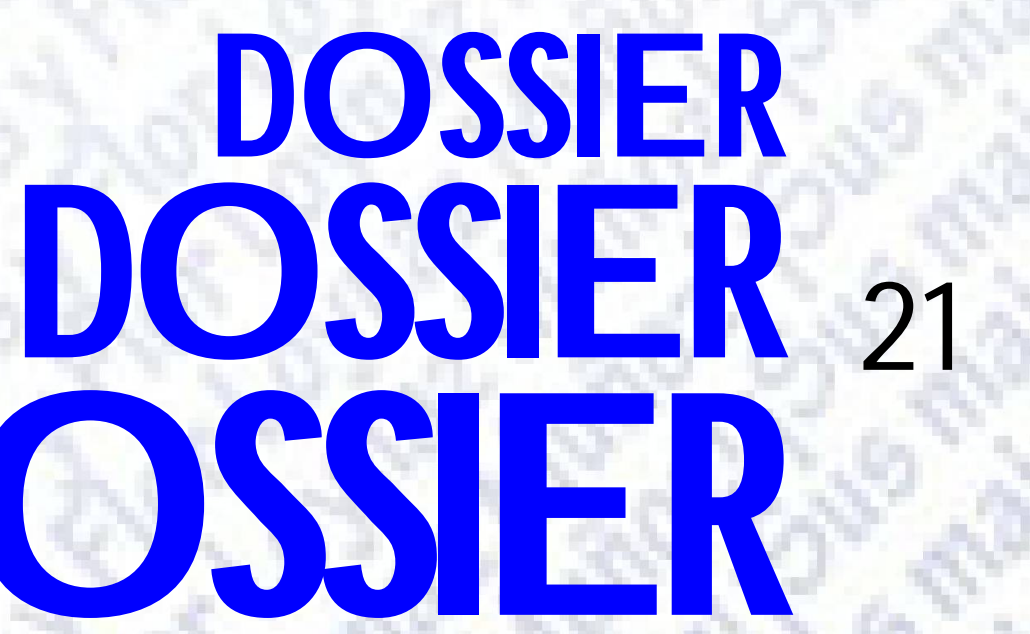

